\title{
Hampered influenza-specific IgG B cell responses whereas IgM and IgA responses are maintained in monoclonal gammopathy of undetermined significance
}

Sarah M. Tete ${ }^{1,2}$, Melissa Newling ${ }^{3}$, Johanna Westra ${ }^{1}$, Aalzen de Haan ${ }^{4}$, Marc Bijl ${ }^{5}$, Surinder S. Sahota ${ }^{2}$ and Nicolaas A. Bos ${ }^{1 *}$

*Correspondence: n.a.bos@umcg.nl

'Department of Rheumatology and Clinical Immunology, University of Groningen, University Medical Center Groningen, Groningen, Netherlands.

${ }^{2}$ Cancer Sciences Academic Unit, University of Southampton School of Medicine, Southampton, UK.

${ }^{3}$ Faculty of Medical Sciences, Biomedical Science, University of Groningen, University Medical Center Groningen, Groningen,

Netherlands.

${ }^{4}$ Department of Medical Microbiology, Molecular Virology section, University of Groningen, University Medical Center Groningen, Groningen, Netherlands.

${ }^{5}$ Department of Internal Medicine and Rheumatology, Martini Hospital, Groningen, Netherlands.

\begin{abstract}
Patients with monoclonal gammopathies frequently have deficient immune function that is conditionrelated. The degree of this immune deficiency increases with progression of disease. As a result, patients with monoclonal gammopathies are prone to infections that include influenza virus. Monoclonal gammopathy of undetermined significance (MGUS) patients with high monoclonal protein elicit poor IgG responses to influenza vaccination. We therefore investigated whether the poor influenza-specific IgG response observed in MGUS translated to poor seroprotection rates in this cohort. Furthermore, we analysed the memory B cell subsets in MGUS as well as quantifying the influenza-specific memory $B$ cells after administration of trivalent inactivated influenza vaccine. Peripheral memory B cell subsets were measured by flow cytometry and stimulated total and influenza-specific memory B cells were detected using an enzyme-linked immunospot (ELISpot) assay at day 0 as well as at day 7 and day 28 post-vaccination. MGUS show low seroprotection rates (37\%) with the Hemagglutination inhibition (HI) response correlating with the lower $\mathrm{H}_{1} \mathrm{~N} 1$-specific IgG titers. The frequency of $\operatorname{IgG}+$ cells in the IgD$\mathrm{CD} 27+$ fraction at day o correlated with the fold increase in HI titers as well as the H1N1-specific IgG titers at day 28 post-vaccination in $\mathrm{HC}$ suggesting a recall memory response. In contrast, the frequency of the $\mathrm{IgG}+$ cells in the IgD-CD27+ fraction is decreased at baseline in MGUS. Furthermore, the frequency of influenza-specific IgG memory B cells is significantly lower post-vaccination in MGUS in comparison to HC, as measured by ELISpot. Despite the poor IgG response, MGUS elicit significant IgM and IgA antibody responses to influenza vaccination. However, the protective capacity of these two antibodies is questionable in MGUS. MGUS is associated with poor IgG memory response that is likely to impair the long maintenance of serologic response.
\end{abstract}

Keywords: Monoclonal gammopathy of undetermined significance, memory B cells, IgG, influenza vaccination

\section{Introduction}

As a precursor condition to multiple myeloma (MM), MGUS does not present with clinical features of MM or other lymphoproliferative malignancies [1]. However, it is characterized by monoclonal immunoglobulin $<30 \mathrm{~g} / \mathrm{L}$, normal to decreased levels of $\mathrm{lgG}$ as well as by $\mathrm{B}$ lymphocyte percentages ranging from low to normal [2-4]. Additionally, there is increased susceptibility to infections in MGUS [5]. Furthermore, immune responses to influenza vaccination vary with M-protein levels as MGUS with high M-protein ( $>15 \mathrm{~g} / \mathrm{L}$ ) has lower influenza-specific $\lg \mathrm{G}$ titers which they fail to expand post-vaccination [6].

Influenza vaccination-induced immunity is primarily antibody

(c) 2014 Bos et al; licensee Herbert Publications Ltd. This is an Open Access article distributed under the terms of Creative Commons Attribution License (http://creativecommons.org/licenses/by/3.0). This permits unrestricted use, distribution, and reproduction in any medium, provided the original work is properly cited. 
Tete et al. Hematology and Leukemia 2014,

http://www.hoajonline.com/journals/pdf/2052-434X-2-5.pdf

doi: $10.7243 / 2052-434 \mathrm{X}-2-5$

based, relying on the activation of naïve $B$ cells as well as the recall of memory $B$ cells (MBCs) to rapidly respond upon re-encounter with antigen. Clonally expanded B cells can differentiate into $\mathrm{MBC}$ s or plasma cells that secrete antibodies at an increased rate as well as with higher affinity for antigen [7]. Several subsets of MBCs have been identified based of the expression of lgD and CD27: IgD-CD27+ classical memory switched (lgG+ or IgA+) cells, CD27+ unswitched memory cells that predominantly express $\lg \mathrm{D}$ and $\lg \mathrm{M}$, but also $\lg M$ only cells. Furthermore, IgD-CD27- (double negative (DN)) memory $B$ cells have been described. Although a definite origin of the different memory $B$ cell subsets remains to be established, it is proposed that isotype switched cells originate from germinal center (GC) reactions while IgM memory may be early emigrants from the GC which began participating in the GC reaction but exited before isotype switching [8]. Alternatively, IgM memory may develop through GCindependent pathways [9]. On the other hand, CD27+lgD+lgM+ cells may represent a recirculating fraction of marginal zone $B$ cells $[9,10]$. Mutated, isotype switched DN B cells contain fewer somatic hypermutations in their immunoglobulin genes and have increased lgG3 use, further distinguishing them from their CD27+ counterparts [11].

Characteristics of the $B$ cell response, and predominantly the nature of long-term B cell memory, are key determining factors of the protective capacity of many vaccines. These MBCs are of importance when the protective efficacy of a vaccine is largely determined by its ability to elicit a humoral response as in influenza vaccination. Indeed, parenteral vaccination with the seasonal trivalent inactivated vaccine induces systemic immune response on which protection is based. The influenza-specific circulating antibodies induced by vaccination decline within 6 months while longer-lasting $M B C s$ remains to respond upon antigen re-encounter, in so doing heightening resistance to infection $[12,13]$.

There is limited data concerning the $B$ cell response to influenza vaccination in MGUS. We evaluated the peak effector responses by measuring antigen-specific titers by both ELISA and hemagglutination nhibition test. Furthermore, we investigated whether the inferior response to influenza vaccination in high monoclonal protein MGUS was associated with alteration in total as well as antigen-specific MBC responses to influenza.

\section{Methods}

\section{Study population}

Patients were included in the study when they fulfilled the standard diagnostic criteria for MGUS [14]. For control purposes, sex and age matched healthy individuals were included parallel to the MGUS patients. Healthy controls with monoclonal protein in their serum were excluded. The patient characteristics have been previously described [6]. All participants included gave written informed consent in accordance with the Declaration of Helsinki. The institutional medical ethics committee of University Medical Centre Groningen approved the study. All MGUS patients and controls received an intramuscular injection of the influenza vaccine (Influvac, Solvay Pharmaceuticals, Netherlands) between October 2010 and January 2011. The vaccine, a subunit preparation of licensed 2010-2011 trivalent inactivated virus, contained A/California/7/2009 (H1N1), A/Perth/16/2009 (H3N2) and B/Brisbane/60/2008.

\section{Cell and serum isolation}

Venous blood samples were obtained at the day of vaccination (day 0), 7 days and 28 days post-vaccination. PBMCs were isolated using CPT vacutainer tubes according to manufacturer's instructions. The PBMCs were frozen in RPMI 1640 (Roswell Park Memorial Institute medium; Lonza, Verviers, Belgium), supplemented with $10 \%$ human pooled serum, $50 \mu \mathrm{g} / \mathrm{mL}$ gentamicin (Gibco, Paisley, UK) and 10\% dimethyl sulfoxide (Merck, Germany) and then stored in liquid nitrogen until further analysis. Serum was separated by centrifugation and stored at $-20^{\circ} \mathrm{C}$ until further analysis.

\section{Influenza-specific IgA and IgM antibodies by ELISA}

The level of anti-influenza specific serum IgA and IgM antibodies against $\mathrm{A} / \mathrm{H} 1 \mathrm{~N} 1$ and $\mathrm{A} / \mathrm{H} 3 \mathrm{~N} 2$ were determined by an in-house enzyme-linked immunosorbent assay (ELISA). ELISA plates (Costar) were coated with $1 \mu \mathrm{g} / \mathrm{mL}$ of $\mathrm{A} / \mathrm{H} 1 \mathrm{~N} 1$ and $\mathrm{A} / \mathrm{H} 3 \mathrm{~N} 2$. The plates were incubated overnight on a shaker. Subsequently, serum samples collected at day 0 , day 7 and day 28 following vaccination were added to the plates and then serially diluted (1:4) in PBS/0.05\% Tween-20/2\% BSA. To detect influenza-specific antibodies, $1 \mu \mathrm{g} / \mathrm{ml}$ goat anti-human IgA-HRP (Southern Biotech) or $1 \mu \mathrm{g} / \mathrm{ml}$ mouse anti-human IgM-HRP (Southern Biotech) conjugate antibodies were used followed by incubation with 3,3'5,5'- tetramethylbenzidine (TMB) substrate. The substrate reaction was stopped by adding $\mathrm{H}_{2} \mathrm{SO}_{4}$ (UMCG pharmacy). Absorbance at 450nm was read with an Emax microplate reader and antibody concentrations calculated by SOFTmax PRO software (Molecular Devices, Sunnyvale, USA). For a standard curve, a dilution series of human IgG standard, N protein (Siemens) was used on every plate and the antibody contents of the samples were read from the linear part of the sigmoid curve.

\section{Hemagglutination inhibition assay}

Hemagglutination Inhibition (HI) test to A/California7/2009/ $\mathrm{H} 1 \mathrm{~N} 1$ was performed according to standard techniques as previously described [15]. The $\mathrm{HI}$ assay was performed using guinea pig erythrocytes and egg-grown influenza viruses as antigens.

\section{Memory B cell assay}

PBMCs were plated in 24-well plates at a cell concentration of $0.5 \times 10^{6}$ cells $/ \mathrm{ml}$ was in RPMI $1640 / 10 \%$ FCS supplemented with $0.1 \mu \mathrm{g} / \mathrm{ml} \mathrm{IL-21} \mathrm{(Immunotools,} \mathrm{Germany),} 0.1 \mu \mathrm{g} / \mathrm{ml} \mathrm{B}$ 
Tete et al. Hematology and Leukemia 2014,

cell activating factor (BAFF) (PeproTech, USA) and $3.2 \mu \mathrm{g} / \mathrm{ml}$ CpG-ODN-2006 (InvivoGen). For negative control PBMCs were cultured in medium (RPMI 1640, supplemented with 50 $\mu$ g/ $\mathrm{mL}$ gentamicin and $10 \% \mathrm{FCS}$ ) alone. Cells were subsequently incubated for 6 days at $37^{\circ} \mathrm{C}, 5 \% \mathrm{CO}_{2}$.

The samples were run in duplicates for detection of cells secreting total IgG antibodies as well as cells secreting TIVspecific lgG. MAIPSWU10 multiscreen filtration plates (Millipore, USA) were pre-wetted with $70 \%$ ethanol for $2 \mathrm{~min}$ and washed 3 times with $150 \mu \mathrm{L} /$ well PBS (phosphate buffered saline; UMCG pharmacy). For coating, TIV (Influvac, Solvay Pharmaceuticals, The Netherlands) was diluted to $1 \mu \mathrm{g} / \mathrm{ml}$ in PBS. To detect total Ig secreting cells, wells were coated with $2.5 \mu \mathrm{g} / \mathrm{ml}$ goat antihuman IgG (Bethyl Laboratories, USA). Wells with PBS only were used as uncoated controls. The plates were incubated overnight at $4^{\circ} \mathrm{C}$. After washing the plates 3 times with 150 $\mu \mathrm{L} /$ well 0,01\% Tween-20 (Sigma-Aldrich, USA), plates were blocked with $2 \% \mathrm{BSA}$ and incubated at $37^{\circ} \mathrm{C}$ for 2 hours. The cultured PBMC were washed thoroughly before counting. The cells were subsequently resuspended in RPMI $1640(+50 \mu \mathrm{g} / \mathrm{mL}$ gentamicin) $/ 10 \%$ FCS and added to the plates in duplicates with $200 \mu \mathrm{l}$ cell suspension/well. The plates were incubated at $37^{\circ} \mathrm{C}$ for 18 hours. After the incubation, cells were discarded and the plates were washed with PBS/0,01\% Tween-20 (6x $150 \mu \mathrm{l} /$ well). Subsequently, $100 \mu \mathrm{L} /$ well anti-human IgG-HRP (Bethyl Laboratories, USA) was added and plates incubated at room temperature for 1 hour. Unbound conjugate antibody was then washed away with PBS $(3 \times 150 \mu \mathrm{l} /$ well $)$ and then developed using TMB substrate (Sanquin, NL) in the dark, at room temperature. To stop the reaction, the plates were washed extensively under the tap and dried in a light-shielded place. Finally, the number of spots per well were quantified with an ELISpot plate reader (A.EL.VIS, Germany).

Immunofluorescent staining and flow cytometric analysis of $B$ cell subsets

PBMCs were counted by the Coulter Counter (Beckman Coulter, USA) and a cell suspension of $2 \times 10^{6} \mathrm{cell} / \mathrm{s} / \mathrm{mL}$ was made. The following monoclonal antibodies were used in this study: CD19 (e-fluor 605), CD24 (PerCP- E-Fluor 710), CD27 (APC-E-Fluor 780), CD38 (PE-Cy7), all obtained from eBioscience. IgG (FITC) from Santa Cruz Biotechnology, IgD (V450) and IgM (APC) were from $\mathrm{BD}$ Biosciences. Cells were incubated with directly conjugated monoclonal antibodies for 60 minutes at $4^{\circ} \mathrm{C}$. After staining, cells were washed with $1 \%$ BSA (Sigma-Aldrich, USA). Nine color flow cytometric analysis was carried out on the BD LSR II (BD Biosciences, USA) with BD FACSDiva Software. Cells were gated on SSC versus FSC to collect lymphocytes and then on CD19 cells versus SSC to gate B cells. Between $0.5 \times 10^{5}$ and $1 \times 10^{6}$ cells were collected. Further analysis for $B$ cell subsets was done by Kaluza (Beckman Coulter, USA). We measured the frequency of CD19+: IgM memory (lgD+/lgM+/CD27+), switched memory B cells (IgD-/CD27+/CD38 low/CD24+) as well as CD27- memory (IgD-/CD27-) and plasmablasts (lgD-/
CD27+/CD38 high/CD24-).

\section{Statistical analysis}

Data analysis was done by Graphpad Prism 5 (Graphpad software). Data are presented as median (range) if not otherwise stated. The Mann-Whitney test was used to compare groups. The Spearman rank test was used to test correlations between variables. Differences were considered statistically significant at $p<0.05$.

\section{Results}

Reduced hemagglutination inhibition response in MGUS We analysed the serum Hemagglutination Inhibition titers before and 28 days after vaccination to evaluate whether the antibody production to one of the seasonal vaccine strains mirrors the responses observed by ELISA analysis. H1N1-specific IgG responses were established in the same MGUS cohort as for this study and were recently reported separately [6]. Hemagglutination inhibition titers were recorded according to criteria used to assess the immunogenicity of influenza vaccines [16]: i.e., seroprotection rates (percentage of vaccinees who achieved titers of $\geq 1: 40$ post-vaccination), seroconversion (the proportion of subjects with a 4 fold or greater rise in antibody titer from the prevaccination titer), Geometric mean titers (GMT) of HIN1 before and post-vaccination and mean fold increase (MFI) in GMT. The inferior response of MGUS patients observed by ELISA was also paralleled by $\mathrm{HI}$ antibody titer response. Correlations between the $\mathrm{HI}$ titer and serum IgG levels were observed at day 28 post-vaccination for healthy controls (Spearman's $r=0.72 ; p=0.008$ ) as well as for MGUS (Spearman's $r=0.58 ; p=0.008$ ) (Figure 1A).

No difference in HI antibody titers between controls $(n=19)$ and MGUS ( $n=19$ ) were detected before vaccination. In both groups, titers of influenza specific antibodies increased after vaccination, but responses were dampened in MGUS $(p=0.07)$. Vaccination resulted in a significant increase in geometric mean titres in $\mathrm{HC}$ from 28.7 at day 0 to 69 at day $28(p=0.0002)$. Similarly, MGUS had an increase in GMT from 27.6 to $45.3(p=0.0005)$. However, these GMTs are low and the fold increase in GMT was lower in MGUS (1.3) compared to healthy controls (2.6) (Figure 1B). The poor increase in antibody titers therefore resulted in lower seroconversion rates, with only 3 (16\%) MGUS patients seroconverting compared to $42 \%$ of healthy controls. The seroprotection rates achieved in healthy controls (58\%) were higher than those achieved in MGUS $(42 \%)$, however without reaching significance $(p=0.06)$.

The frequency of TIV-specific IgG memory B cells does not increase following vaccination in MGUS

We have analysed the composition of the peripheral B cell pool in $5 \mathrm{HC}$ and 6 MGUS patients in which additional PBMCs were available. To further explore influenza vaccination-induced alterations in the B cell compartment, we compared circulating $B$ cell subsets at baseline to those obtained post-vaccination 


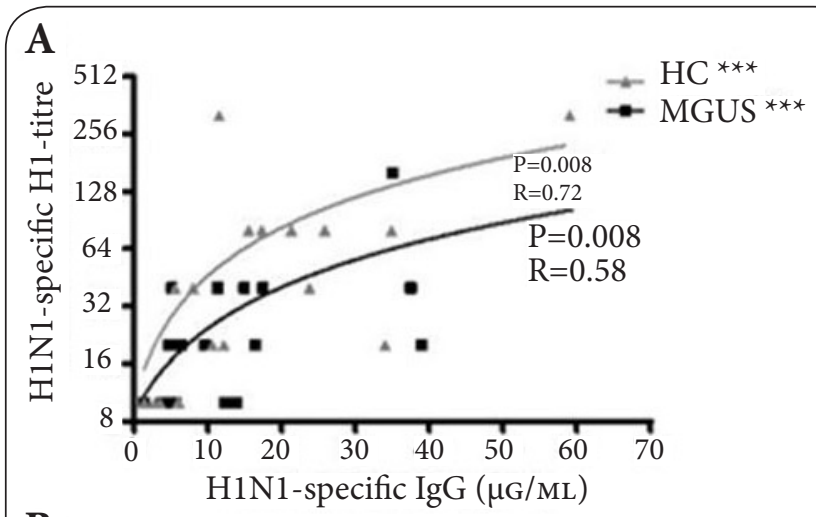

B

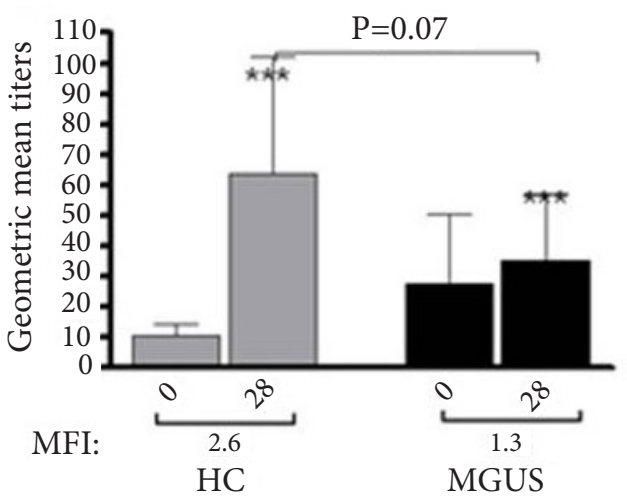

Figure 1. Hemagglutination inhibition antibody responses of HC and MGUS to H1N1 component of 2010 TIV.

(A) Correlation curve for H1N1 HI titer and H1N-specific IgG in HC (grey triangles) and MGUS (black squares) at day 28. (B) Geometric mean titers against H1N1 (A/California/ $7 / 2009)$ at day 0 and day 28 post-vaccination for $\mathrm{HC}(\mathrm{n}=19)$ and MGUS $(n=19)$. Bars and error bars denote group median and interquartile range. Mean fold increase in GMT is shown as numerical values below. ${ }^{* *} \mathrm{p}<0.01 ;{ }^{* * *} \mathrm{p}<0.001$.

(day 7 and day 28). No statistically significant difference in the relative frequencies of CD27+ memory B cells and plasmablasts was observed between $\mathrm{HC}$ and MGUS at baseline (data not shown). Following vaccination, the frequencies of the $B$ cell subsets remained relatively constant in $\mathrm{HC}$ except for plasmablasts which showed a trend to an increase (but not statistically significant) at day 7 post-vaccination (data not shown).

Additionally, to investigate immunoglobulin expression on $B$ cells, we evaluated the expression of IgG on IgD-CD27+ $B$ cells. At baseline, the majority of the cells were of IgG isotype for both $\mathrm{HC}$ and MGUS. However, the frequency of these lgG+ cells was significantly lower in MGUS compared with HCs $(p=0.05)$ (Figure 2A). The lower frequency of IgG+ cells in the IgD-CD27+ fraction in MGUS at baseline was due to a concomitant increase in lgM+ cells in the lgD-CD27+ fraction $(p=0.0037)$.

Furthermore, The frequency of these lgG+ cells in the CD27+ $B$ fraction demonstrated positive associations with the H1N1specific serum lgG at day 28 in HCs (Spearman's $r=0.7033$, $\mathrm{p}=0.0073$ ) (Figure 2B). Following vaccination (day 7), there was a significant decrease in the frequency of $\lg G+\operatorname{lgD}-C D 27+$ cells in $\mathrm{HC}(p=0.04)$, however the decrease was not significant in MGUS. This decrease in lgG+ lgD-CD27+ cells in HC may be due to the mobilization of these lgG+ cells from the peripheral blood to secondary lymphoid organs as well as mucosal sites. Additionally, the frequency of $\mathrm{lgG}+$ in the isotype-switched CD27+ fraction at day 0 was positively correlated with the fold increase in hemagglutination inhibition titers at day 28 in HCs only (Spearman's $r=0.5522, p=0.0328$ ) (Figure 2C). Therefore, the increase in influenza-specific lgG titers is associated with higher numbers of total lgG+CD27+ cells.

Influenza-specific memory B cell levels are expressed as the frequency of total IgG-switched memory B cells (total IgG secreting cells) to normalize the data for differences in cell recovery as well as for changes in the overall memory $B$ cell population. In order to detect the effect of influenza vaccination, we assayed the number of influenza-specific IgG MBCs at day 7- and day 28 post-vaccination. There were detectable TIV-specific lgG memory B cells at baseline for both $\mathrm{HC}$ (range 12 to 74 per $10^{5} \mathrm{PBMCs}$ ) and MGUS (range 0 to 106 per $10^{5}$ PBMCs). However, TIV-specific Ig memory B cells were absent in 1 MGUS patient at baseline. The TIV-specific IgG memory B cells averaged 4.1\% (1.6- 7.2) of total IgG memory $\mathrm{B}$ cells in $\mathrm{HC}$ and $2.6 \%(0-5.6)$ in MGUS. Vaccination resulted in a significant increase in the frequency of TIV-specific lgG memory B cells in $\mathrm{HC}(\mathrm{p}=0.03)$ but not in MGUS at day 7 postvaccination. This resulted in $\mathrm{HC}$ having significantly higher percentages of TIV-specific lgG memory B cells $(p=0.03)$ that averaged $17 \%$ of total IgG memory B cells in comparison to $4.3 \%$ in MGUS where the frequencies of the TIV-specific lgG memory B cells did not show a significant increase (Figure 2D). Of note is that the number of total lgG memory $B$ cells at day 28 post-vaccination negatively correlate with monoclonal protein concentration (Spearman's $r=-0.87, p=0.03$ ) (data not shown).

\section{MGUS patients mount significant IgA and IgM response to influenza vaccination}

Baseline frequencies of DN (IgD-CD27-) memory B cells as well as $\lg M+\lg D+C D 27+$ memory $B$ cells were comparable between $\mathrm{HC}$ and MGUS. However, vaccination resulted in an increase in the frequency of DN memory B cells at day 7 in MGUS ( $p=0.01$ ) (Figure 3A). Furthermore, $\lg M+\lg D+C D 27+$ memory $B$ cells were decreased in MGUS in response to vaccination at day $7(p=0.01)$ (Figure 3B). This decrease at day 7 post-vaccination may indicate a difference in responding cells in comparison to $\mathrm{HCs}$ as the frequency of these cells is lower than those in $\mathrm{HC}$ at the same time-point $(p=0.009)$.

We further examined humoral immune responses in $19 \mathrm{HC}$ and 19 MGUS patients. We determined the H1N1 influenzaspecific $\lg \mathrm{M}$ and $\lg \mathrm{A}$ antibody responses before vaccination (day 0 ) as well as after vaccination (day 7 and day 28 postvaccination). Influenza-specific $\lg M$ and $\lg A$ were detected 
Tete et al. Hematology and Leukemia 2014,

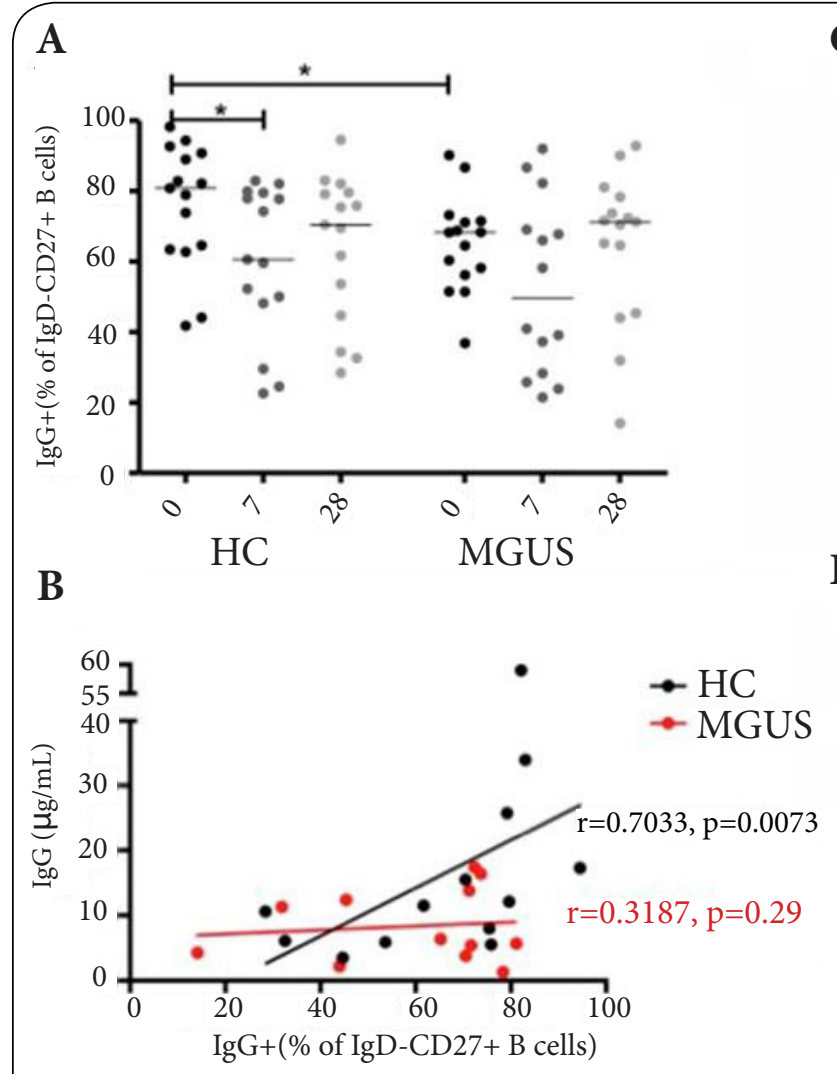

C

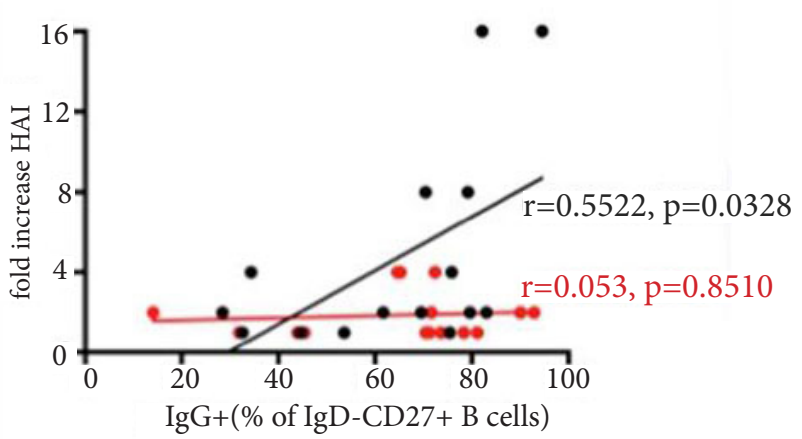

D

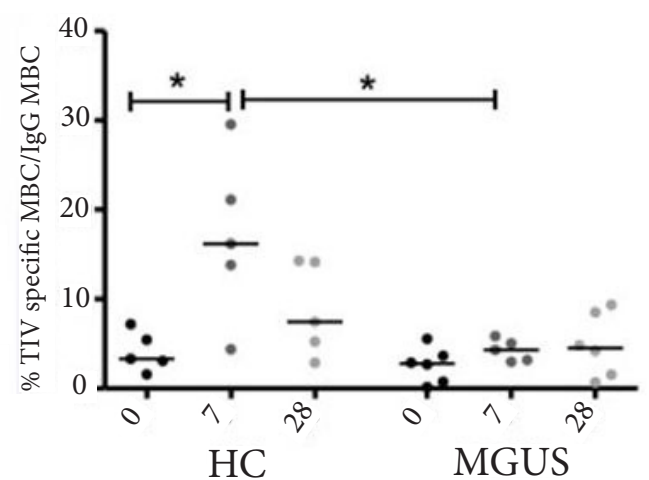

Figure 2. Analysis of influenza vaccination-induced changes in IgG responses.

(A)The changes in frequencies of IgG+ IgD- CD27+ cells in response to influenza vaccine challenge in HC and MGUS at day 0 , day 7 and day 28 . The frequency of the IgG+ (CD27+ cells) correlates with (B) IgG titers and (C) the fold increase in HAI in HC. (D) IgG secreting TIV-specific memory B cells in HC and MGUS at day 0 , day 7 and day 28 post-vaccination. The number of TIV-specific memory B cells was calculated as a \% of total IgG secreting MBCs. ${ }^{\star} \mathrm{p}<0.05$.

at baseline in both $\mathrm{HCs}$ and MGUS. Vaccination resulted in a significant increase in both $\lg M(p=0.0009)$ and $\lg A(p=0.005)$ levels at day 7 post-vaccination in $\mathrm{HCs}$ with the levels being maintained at day 28 post-vaccination. Similarly, MGUS showed an increase in $\mathrm{H} 1 \mathrm{~N} 1$ influenza-specific $\lg \mathrm{M}(\mathrm{p}=0.002)$ (Figure $3 \mathrm{C}$ ) and $\lg A(p=0.0003)$ (Figure 3D) antibody titers at day 7 . However, MGUS had a trend to higher day 7 IgM titers in comparison to $\mathrm{HCs}$, though not statistically significant $(p=0.07)$.

\section{Discussion}

Serum titers of hemagglutination inhibiting antibodies are an universally established correlate of protection for influenza with seroprotection rate accepted as a proxy end point $[17,18]$. The $\mathrm{HI}$ results in our study confirmed hampered vaccine-specific antibody responses as observed by IgG ELISA as we showed that MGUS had reduced $\mathrm{HI}$ response. Moreover, $\mathrm{H} 1 \mathrm{~N} 1$ specific IgG antibody levels correlate with the $\mathrm{HI}$ response [6]. The poor post-vaccination influenza specific lgG antibody levels observed in MGUS may therefore predict or mirror response to influenza vaccination. The seroprotection rate was lower in MGUS (37\%) in comparison to age matched HCs (58\%) suggesting that these MGUS patients are likely to be less protected by vaccination.

After TIV vaccination, naïve and memory $B$ cells that encounter antigen differentiate into effector $B$ cells that appear in the circulation and peak around day 7 and subsequently decline [19]. In this study, we see a non-significant increase in total plasmablasts at day 7 post-vaccination in both $\mathrm{HC}$ and MGUS. However, we did not selectively look at influenzaspecific antibody secreting cells to determine the association between the serum response and effector cells. We observed TIV specific MBCs in both HC and MGUS before vaccination. This is in agreement with other studies where pre-existing influenza specific MBCs are present in the circulation [20] and reflect prior vaccination or natural infection. Previous reports have shown that following polyclonal stimulation and ELISpot, antigen-specific lgG MBCs account for up to $6 \%$ of the total IgG memory at day30 post-vaccination $[19,20]$. The responses we observed in this study were higher with TIV-specific MBCs making up to $29 \%$ of total IgG MBCs at day 7 and up to $14 \%$ at day 28 post-vaccination in HCs. The differences in the immune responses observed could be due to the differences in the composition of the TIV vaccines in the various years. Furthermore, all the $\mathrm{HC}$ and MGUS patients in this study were 
Tete et al. Hematology and Leukemia 2014,
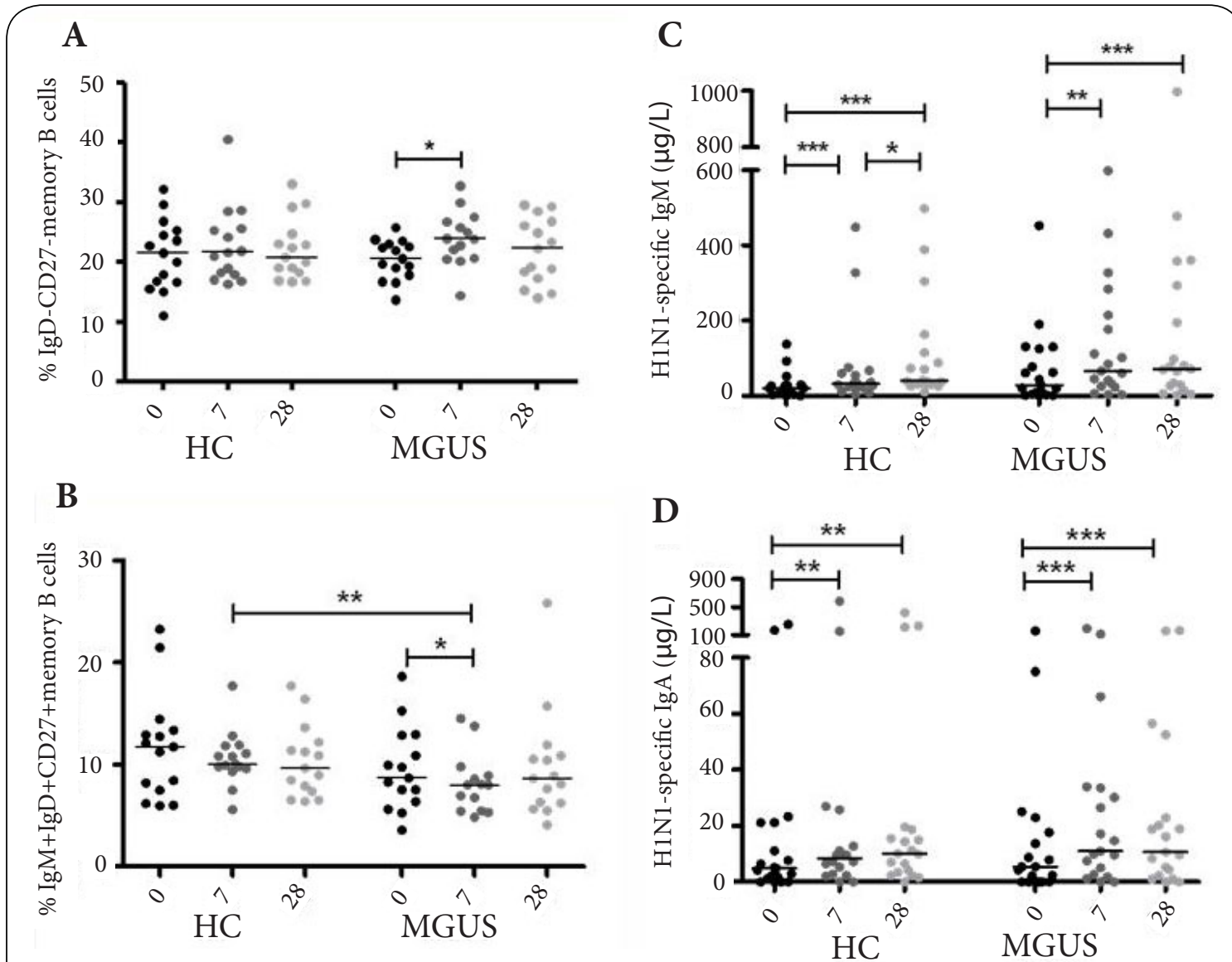

Figure 3. Effect of influenza vaccination upon peripheral $B$ cell subset proportions and antibody titers. Frequencies of (A) IgD- CD27- memory B cells and (B) IgM+ IgD+CD27+ memory B cells at day 0, day 7- and day 28 post-vaccination. Vaccination results in a significant increase in H1N1-specific $\operatorname{IgM}(\mathbf{C})$ and as well as $\operatorname{IgA}$ (D) in both HC and MGUS. ${ }^{*} \mathrm{p}<0.05 ;{ }^{* *} \mathrm{p}<0.01 ;{ }^{* *} \mathrm{p}<0.001$.

vaccinated the previous year with $\mathrm{A} /$ California/2009 that was present in the current TIV. Therefore, a recall response was likely to be elicited. Another difference is that the previous studies used Staphylococcus aureus Cowan, CpG and Pokeweed mitogen $[19,21]$ as polyclonal stimuli while we used IL-21, BAFF and CpG. There may therefore be differences in the $M B C$ activation efficiency between the assays. However this discrepancy was accounted for by measuring the frequencies of TIV-specific MBC in the activated total MBC population rather than as numbers of TIV-specific MBC per stimulated PBMCs.

The expansion of MBCs following vaccination is enriched for antigen-specific cells in HC. However, vaccination did not result in a significant increase in antigen-specific MBCs in MGUS. This poor antigen-specific memory response is likely to impair the maintenance of serologic response [22]. Notably, MGUS had lower frequencies of IgG+ IgD- CD27+ cells at baseline and influenza-specific lgG secreting cells are significantly lower in response to vaccination. Moreover, the higher levels of IgG+lgD-CD27+ cells in $\mathrm{HC}$ at baseline were associated with higher fold-increase in the $\mathrm{HI}$ titers but not for MGUS implying that higher frequency of IgG+lgD-CD27+ cells are advantageous for antibody responses. Interestingly, we noted that in a subset of MGUS assayed by ELISpot, high monoclonal protein concentration is associated with lower (total) IgG MBCs following vaccination. This implies that, at least in this small subset of MGUS, high monoclonal protein concentration is associated with a limited humoral immunologic memory that will potentially limit the response to influenza vaccination.

In the IgD-CD27+ fraction, there is a decrease in the frequency of IgG+ cells that is compensated by an increase in $\lg M+$ cells in MGUS at day 0 before vaccination. This may then limit the repertoire of lgG+ cells that is available to respond to vaccination. While, there is evidence of hampered IgG responses in MGUS, the IgM response is not negatively affected. Indeed, serum H1N1-specific IgM titers in MGUS were comparable to $\mathrm{HC}$ as they also increased following vaccination. Furthermore, the change in frequencies in lgM+ (IgD+CD27+) memory B cells frequencies at day 7 may reflect differences in responding cells between $\mathrm{HCs}$ and MGUS. Some IgM memory B cells may differentiate into cross-reactive lgM antibody secreting cells leading to the increase in $\mathrm{H} 1 \mathrm{~N} 1$ - 
Tete et al. Hematology and Leukemia 2014,

specific $\lg \mathrm{M}$ as observed. The rest of the $\lg \mathrm{M}$ memory may be recruited into the secondary response to compensate for the hampered lgG response.

Interestingly, DN memory B cells are also substantially expanded in the peripheral blood of MGUS at day 7, suggesting their participation in the early phase of memory responses although their antigen specificity was not determined. Whether distinct pathways are responsible for the induction of CD27and CD27+ memory $B$ cells after antigen challenge remain debatable. However, these CD27- memory B cells may result from incomplete germinal center reactions therefore explaining their failure to acquire CD27 $[\mathbf{2 3}, \mathbf{2 4}]$. This also explains their lower somatic hypermutation rates in comparison to CD27+ counterparts $[\mathbf{2 5}, \mathbf{2 6}]$. A study by Moir and colleagues showed that influenza-specific IgG MBC can be found in the CD27compartment albeit at frequencies 10 times lower than in the CD27+ compartment of $\mathrm{HC}$ [25]. This would suggest that the influenza-specific response within the CD27-lgG+ B-cell subset would not be as effective as from its CD27+ counterpart.

We analyzed the relationship between memory response to influenza vaccination as well as the peripheral blood B cell subsets as they are easily accessible. However, by measuring peripheral blood B-cell subsets instead of antigen-specific $B$ cells we indirectly assess the cells involved in the response to vaccination. Another limitation was the small group sizes of the $\mathrm{HC}$ and MGUS included in the different analyses. Nevertheless, we found several differences between the HC and MGUS but larger sample sizes are needed to confirm our results.

\section{Conclusion}

We have shown that MGUS elicit a significant IgM and IgA antibody responses to influenza vaccination despite the restricted IgG B cell response. Poor antigen-specific memory response in MGUS is likely to impair the maintenance of serologic response. The poor lgG memory response is related to high monoclonal protein in MGUS suggesting defect in $B$ cell immunity.

\section{Competing interests}

The authors declare that they have no competing interests.

Authors' contributions

\begin{tabular}{|l|c|c|c|c|c|c|c|}
\hline Authors' contributions & ST & MN & JW & AH & SS & MB & NB \\
\hline Research concept and design & -- & -- & -- & -- & $\checkmark$ & $\checkmark$ & $\checkmark$ \\
\hline Collection and/or assembly of data & $\checkmark$ & $\checkmark$ & -- & -- & -- & -- & -- \\
\hline Data analysis and interpretation & $\checkmark$ & $\checkmark$ & $\checkmark$ & $\checkmark$ & -- & -- & $\checkmark$ \\
\hline Writing the article & $\checkmark$ & -- & -- & -- & -- & -- & $\checkmark$ \\
\hline Critical revision of the article & $\checkmark$ & $\checkmark$ & $\checkmark$ & $\checkmark$ & $\checkmark$ & $\checkmark$ & $\checkmark$ \\
\hline Final approval of article & $\checkmark$ & $\checkmark$ & $\checkmark$ & $\checkmark$ & $\checkmark$ & $\checkmark$ & $\checkmark$ \\
\hline Statistical analysis & $\checkmark$ & -- & -- & -- & -- & -- & -- \\
\hline
\end{tabular}

Acknowledgement

We thank the staff of Rheumatology and Clinical immunology for technical assistance and their support of the original study. We are also grateful to the patients and volunteers for participating in this study. S.T was supported by an EU phD scholarship.

\section{Publication history}

Editor: Takashi Kumagai, Ohme Municipal General Hospital, Japan. EIC: Evangelos Terpos, University of Athens School of Medicine, Greece.

Received: 28-Jun-2014 Final Revised: 11-Sep-2014

Accepted: 04-Oct-2014 Published: 11-Oct-2014

\section{References}

1. Kyle RA, Therneau TM, Rajkumar SV, Offord JR, Larson DR, Plevak MF and Melton LJ, 3rd. A long-term study of prognosis in monoclonal gammopathy of undetermined significance. N Engl J Med. 2002; 346:564-9. | Article | PubMed

2. Blade J, Rosinol L, Cibeira MT and de Larrea CF. Pathogenesis and progression of monoclonal gammopathy of undetermined significance. Leukemia. 2008; 22:1651-7. | Article | PubMed

3. Gregersen H, Mellemkjaer L, Ibsen JS, Dahlerup JF, Thomassen L and Sorensen HT. The impact of $\mathrm{M}$-component type and immunoglobulin concentration on the risk of malignant transformation in patients with monoclonal gammopathy of undetermined significance. Haematologica. 2001; 86:1172-9. | Article | PubMed

4. Pessoa de Magalhaes RJ, Vidriales MB, Paiva B, Fernandez-Gimenez C, Garcia-Sanz R, Mateos MV, Gutierrez NC, Lecrevisse Q, Blanco JF, Hernandez J, de las Heras N, Martinez-Lopez J, Roig M, Costa ES, Ocio EM, Perez-Andres M, Maiolino A, Nucci M, De La Rubia J, Lahuerta $\mathrm{JJ}$, San-Miguel JF and Orfao A. Analysis of the immune system of multiple myeloma patients achieving long-term disease control by multidimensional flow cytometry. Haematologica. 2013; 98:79-86. Article | PubMed Abstract | PubMed Full Text

5. Kristinsson SY, Tang M, Pfeiffer RM, Bjorkholm M, Goldin LR, Blimark C, Mellqvist UH, Wahlin A, Turesson I and Landgren O. Monoclonal gammopathy of undetermined significance and risk of infections: a population-based study. Haematologica. 2012; 97:854-8. | Article | PubMed Abstract | PubMed Full Text

6. Tete S M, Wilting KR, Horst G, Klijn MA, Westra J, de Haan A, Huckriede AL, Kluin-Nelemans HC, Sahota SS and Bijl M. IgG antibody and TH1 immune responses to influenza vaccination negatively correlate with M-protein burden in monoclonal gammopathy of undetermined significance. Hematology and Leukemia. 2013; 1:3. | Article

7. Lanzavecchia A, Bernasconi N, Traggiai E, Ruprecht CR, Corti D and Sallusto F. Understanding and making use of human memory B cells. Immunol Rev. 2006; 211:303-9. | Article | PubMed

8. Tangye SG and Good KL. Human IgM+CD27+ B cells: memory B cells or "memory" B cells? J Immunol. 2007; 179:13-9. I Article I PubMed

9. Weller S, Braun MC, Tan BK, Rosenwald A, Cordier C, Conley ME, Plebani A, Kumararatne DS, Bonnet D, Tournilhac O, Tchernia G, Steiniger B, Staudt LM, Casanova JL, Reynaud CA and Weill JC. Human blood IgM "memory" B cells are circulating splenic marginal zone B cells harboring a prediversified immunoglobulin repertoire. Blood. 2004; 104:3647-54. | Article | PubMed Abstract | PubMed Full Text

10. Dunn-Walters DK, Isaacson PG and Spencer J. Analysis of mutations in immunoglobulin heavy chain variable region genes of microdissected marginal zone (MGZ) B cells suggests that the MGZ of human spleen is a reservoir of memory B cells. J Exp Med. 1995; 182:559-66. | Article | PubMed Abstract | PubMed Full Text

11. Wu YC, Kipling D, Leong HS, Martin V, Ademokun AA and Dunn-Walters DK. High-throughput immunoglobulin repertoire analysis distinguishes between human IgM memory and switched memory B-cell populations. Blood. 2010; 116:1070-8. | Article | PubMed Abstract | PubMed Full Text

12. Kunzel W, Glathe $H$, Engelmann $H$ and Van Hoecke $C$. Kinetics of humoral antibody response to trivalent inactivated split influenza vaccine in subjects previously vaccinated or vaccinated for the first time. Vaccine. 1996; 14:1108-10. | Article | PubMed

13. Wrammert J, Smith K, Miller J, Langley WA, Kokko K, Larsen C, Zheng 
Tete et al. Hematology and Leukemia 2014,

NY, Mays I, Garman L, Helms C, James J, Air GM, Capra JD, Ahmed R and Wilson PC. Rapid cloning of high-affinity human monoclonal antibodies against influenza virus. Nature. 2008; 453:667-71. | Article | PubMed Abstract | PubMed Full Text

14. International Myeloma Working Group. Criteria for the classification of monoclonal gammopathies, multiple myeloma and related disorders: a report of the International Myeloma Working Group. Br J Haematol. 2003; 121:749-57. | PubMed

15. WHO, Global Influenza Surveillance Network. Manual for the laboratory diagnosis and virological surveillance of influenza. | Website

16. European agency for the evaluation of medicinal products (EMEA):Note for guidance on harmonization of requirements for influenza vaccines. I $\underline{P d f}$

17. Hobson D, Curry RL, Beare AS and Ward-Gardner A. The role of serum haemagglutination-inhibiting antibody in protection against challenge infection with influenza A2 and B viruses. J Hyg (Lond). 1972; 70:767-77. | Article | PubMed Abstract | PubMed Full Text

18. Gross PA, Hermogenes AW, Sacks HS, Lau J and Levandowski RA. The efficacy of influenza vaccine in elderly persons. A meta-analysis and review of the literature. Ann Intern Med. 1995; 123:518-27. | Article PubMed

19. Sasaki S, Jaimes MC, Holmes TH, Dekker CL, Mahmood K, Kemble GW, Arvin AM and Greenberg HB. Comparison of the influenza virus-specific effector and memory B-cell responses to immunization of children and adults with live attenuated or inactivated influenza virus vaccines. $J$ Virol. 2007; 81:215-28. | Article | PubMed Abstract | PubMed Full Text

20. Sasaki S, He XS, Holmes TH, Dekker CL, Kemble GW, Arvin AM and Greenberg HB. Influence of prior influenza vaccination on antibody and B-cell responses. PLoS One. 2008; 3:e2975. | Article | PubMed Abstract | PubMed Full Text

21. Crotty S, Aubert RD, Glidewell J and Ahmed R. Tracking human antigenspecific memory B cells: a sensitive and generalized ELISPOT system. J Immunol Methods. 2004; 286:111-22. | Article I PubMed

22. Bernasconi NL, Traggiai E and Lanzavecchia A. Maintenance of serological memory by polyclonal activation of human memory B cells. Science. 2002; 298:2199-202. | Article | PubMed

23. Blink EJ, Light A, Kallies A, Nutt SL, Hodgkin PD and Tarlinton DM. Early appearance of germinal center-derived memory B cells and plasma cells in blood after primary immunization. J Exp Med. 2005; 201:545-54. | Article | PubMed Abstract | PubMed Full Text

24. Fecteau JF, Cote G and Neron S. A new memory CD27-IgG+ B cell population in peripheral blood expressing VH genes with low frequency of somatic mutation. J Immunol. 2006; 177:3728-36. | Article | PubMed

25. Moir S, De Ravin SS, Santich BH, Kim JY, Posada JG, Ho J, Buckner CM, Wang W, Kardava L, Garofalo M, Marciano BE, Manischewitz J, King LR, Khurana S, Chun TW, Golding H, Fauci AS and Malech HL. Humans with chronic granulomatous disease maintain humoral immunologic memory despite low frequencies of circulating memory B cells. Blood. 2012; 120:4850-8. | Article | PubMed Abstract | PubMed Full Text

26. Wu YC, Kipling D and Dunn-Walters DK. The relationship between CD27 negative and positive $B$ cell populations in human peripheral blood. Front Immunol. 2011; 2:81. | Article | PubMed Abstract | PubMed Full $\underline{\text { Text }}$

\section{Citation:}

Tete SM, Newling M, Westra J, de Haan A, Bijl M, Sahota SS and Bos NA. Hampered influenza-specific IgG $B$ cell responses whereas IgM and IgA responses are maintained in monoclonal gammopathy of undetermined significance. Hematol Leuk. 2014; 2:5. http://dx.doi.org/10.7243/2052-434X-2-5 